\title{
Acting Agentically at Work: Developing a Short Measure of Professional Agency'
}

I Katja Vähäsantanen ${ }^{2}$

University researcher, University of Jyväskylä, Department of Education, Finland

I Eija Räikkönen

Senior lecturer, University of Jyväskylä, Faculty of Education and Psychology, Finland

\section{Susanna Paloniemi}

Senior lecturer, University of Jyväskylä, Department of Education, Finland

\section{Päivi Hökkä}

University researcher, University of Jyväskylä, Department of Education, Finland

\begin{abstract}
Although professional agency has become an increasingly crucial issue in work organizations, investigators lack a brief instrument to measure it. This paper introduces a short measure to explore professional agency at work. Our aim was to shorten the original 17-item Professional Agency Measure, while also exploring its usability for cross-validating questionnaire datasets, and investigating the relationship between professional agency and work engagement. Three dimensions of professional agency emerged, with three items per dimension, across the domains of healthcare, real estate services, and information technology (all within Finland). All the dimensions (Influencing at work, Participation at work, and Negotiating professional identity) showed good reliability. The results further revealed that these dimensions of agency are distinct from, but closely and positively linked to work engagement. In particular, our research offers a reliable, short measure of professional agency that is relevant across professional domains in the Nordic context.
\end{abstract}

\section{KEYWORDS}

Professional agency / professional agency measure / short-form instrument / work engagement

\section{Introduction}

mid societal, economic, and technological changes in working life, employees are, in the best case, agentic actors who enact professional agency rather than operating as pawns in work organizations. In other words, they do not simply respond to certain allotted work responsibilities and environments; rather, they are active and influential constructors of the work practices, environments, careers, and identities pertaining to their work (Billett 2011; Eteläpelto 2017; Harteis et al. 2020; Tynjälä 2013). In line with agentic notions on professionals within work settings, researchers have paid increasing

\footnotetext{
${ }^{1}$ You can find this text and its DOI at https://tidsskrift.dk/njwls/index.

${ }^{2}$ Corresponding author: katja.vahasantanen@jyu.fi.
} 
attention to professional agency, focusing on its importance for the development, innovativeness, and success of organizations, and for the learning, creativity, and wellbeing of the professionals who work in them (Damsa et al. 2017; Goller \& Paloniemi 2017; Haapasaari \& Kerosuo 2015; Vähäsantanen et al. 2017b). Agency is also at the heart of discussions regarding career and identity in the processes of changing working life (LaPointe \& Heilmann 2014; Vähäsantanen et al. 2017a).

In workplace learning and working life studies, professional agency refers to the notion that professionals act, participate, and belong within social communities, and that they have the power to affect matters and to make decisions, for example in relation to their work and professional identities (e.g. Goller \& Billett 2014; Goller \& Paloniemi 2017; Heiskanen \& Jokinen 2015). To date, emergent discussions on professional agency have mostly been based on qualitative research, and the topic has not generally been addressed via quantitative measures within working life (for exceptions, see Goller 2017). However, it should be noted that the notion of employees as active agents in their work environment has a long tradition in the field of work psychology, within which many instruments have been introduced, covering constructs such as influence at work and job crafting (e.g. Gallie 2009; Tims et al. 2012). In contrast with these related constructs, professional agency research has placed a stronger emphasis on professional identity.

With a view to contributing to research on agency at work, Vähäsantanen et al. (2019) introduced the Professional Agency Measure (PAM), the theoretical basis of which was a subject-centred sociocultural approach (Eteläpelto et al. 2013). In line with this, professional agency is regarded primarily as an action-based phenomenon, enacted towards both work and professional identity. However, such agency cannot be seen as divorced from social environments with their affordances and restrictions, to the extent that one might view the individual alone as the starting point for an action. Altogether, PAM comprises 17 items, and aims at investigating three dimensions of professional agency, namely Influencing at work, Developing work practices, and Negotiating professional identity. A previous study by Vähäsantanen et al. (2019) showed that the measure displayed fairly good convergent and divergent validity in relation to the constructs of Learning at work and Emotionally meaningful work. However, the research also suggested a need to test the functionality of some of the items which, for example, crossloaded on two dimensions (for more information, see the section on Measures). In the present study, we sought to confirm the items that were most applicable to these dimensions, in line with our aim to shorten the original PAM and increase its ecological validity. With this in view, we conducted our study in three different professional domains.

From a pragmatic perspective, in seeking to address practical limitations on time and resources, there is a need to further develop research instruments (e.g. Stanton et al. 2002). In particular, there is a need to shorten the measurement procedure, insofar as briefer versions reduce participants' fatigue, and address problems of low participation (e.g. Burisch 1984).

Starting from these considerations, this study entailed developing a short measure to explore professional agency in work organizations, based on the original PAM (Vähäsantanen et al. 2019). Hence, the study investigated the factor structure and validity of the modified instrument, using datasets from the professional domains of healthcare, real estate services, and information technology (IT). The questionnaire data were collected in Finland.

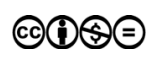


The study also aimed to examine the relationship between professional agency and work engagement, with a view to exploring the discriminant and convergent validity of the short PAM. From the perspective of developing a measure, we see it as pivotal to identify a difference (or possible overlap) between professional agency and work engagement, since these constructs both cover individuals' experiences of their work, albeit from different perspectives. Professional agency can be seen theoretically as a more sociocultural and action-based phenomenon (Eteläpelto et al. 2013). Work engagement appears rather to be a psychological and emotion-related phenomenon, taking the form of a positive emotional affective-cognitive state, and characterized by vigor, dedication, and absorption (Schaufeli et al. 2002, 2006). The possible connectedness of these constructs merits investigation, and could lead to new research avenues within Nordic working life studies. It should be noted that there has so far been no empirical evidence on the relationship between professional agency and work engagement. However, previous research has given some indications of their connectedness, with professional agency emerging as related to constructs such as wellbeing and motivation, and to emotions such as feeling enthusiastic at work (e.g. Eteläpelto et al. 2013; Ursin et al. 2021) - all of which seem to resonate with work engagement. The following sections will examine professional agency, work engagement, and their relationship in more depth.

Previewing the outcomes of our research, we would claim (i) that it offers a reliable, short measure of professional agency, relevant to working life research across a variety of professional domains in Nordic countries, (ii) that it contributes to current theory on professional agency by confirming the three-dimensional structure of professional agency, in conjunction with a coherent and theoretically valid definition, and (iii) that it reveals a positive connection between professional agency and work engagement.

\section{Professional agency in work environments}

In current literature, professional agency has been conceptualized in several ways in working life research, and via a range of theoretical approaches, utilizing psychological, sociological, and sociocultural theories (see Damsa et al. 2017; Eteläpelto et al. 2013; Heiskanen \& Jokinen 2015). In particular, professional agency has been approached from two perspectives (Paloniemi \& Goller 2017), as follows.

In the first place, considering agency as an individual feature, one can view it as encompassing individuals' dispositions, capabilities, and competencies that direct selfinitiated and goal-directed behaviour in work environments (e.g. Goller 2017). Secondly, and more frequently, professional agency is understood as consisting of agentic behaviour and activities in working life contexts (Paloniemi \& Goller 2017). Such behavioural agency is mainly conceptualized as a matter of exerting influence and making decisions regarding work-related matters, and also as participation in professional environments (Billett 2011; Smith 2012). Behavioural agency is further understood in terms of transformative activities, rather than as a matter of merely maintaining an existing state of work-related affairs in social interaction (Damsa et al. 2017; Eteläpelto 2017). Thus, agency in work environments is notably conceptualized as commenting and asking questions, taking stances on a current state of affairs, making suggestions for novel work practices, and developing products, services, and processes within the work (Collin et al. 
2015; Haapasaari \& Kerosuo 2015). Overall, one could say that agency is mostly conceptualized as pertaining to work practices and environments.

Nevertheless, professional agency has also been viewed as closely connected to professional identity, which encompasses professional values, interests, goals, and commitments at work. It follows that agentic behaviour covers the enactment of professional interests and goals, taking a new direction at work, (trans)forming and strengthening an understanding of oneself as a professional, and orienting oneself towards future learning (Ruohotie-Lyhty \& Moate 2016; Vähäsantanen et al. 2017a). Furthermore, agency tends to manifest itself as making active choices and decisions concerning one's individual career construction, direction, and pathways (e.g. LaPointe \& Heilmann 2014).

In this study, in line with the theoretical notions above and the subject-centred socio-cultural approach (Eteläpelto et al. 2013), we viewed professional agency primarily as a behavioural phenomenon, that is as something that people do and enact in working life. In this sense, agency is closely associated with actions and occurs in the relations between individuals and contexts. Thus, we do not understand agency as a trait or capacity, but as a socioculturally and situationally constructed action-based phenomenon (see also Eteläpelto 2017). In line with this kind of theoretical understanding, the original version of PAM was designed and validated with a view to exploring the multidimensional structure of professional agency (Vähäsantanen et al. 2019), and as encompassing Influencing at work, Developing work practices, and Negotiating professional identity. These dimensions are presented briefly below. The original assumption was that the structure of professional agency includes six theoretically assumed dimensions; however, empirical research indicated that it could be better encompassed by three dimensions, as set out below.

Influencing at work. This dimension includes the notion of professionals who exert influence (i) through making decisions that cover both individual work and shared workrelated matters in their work environments, and (ii) through the presentation of views and opinions that are truly heard and recognized at work (e.g. Billett 2008). Originally, it included two theoretically based dimensions (Decision making at work and Being heard at work), but the empirical investigation revealed that these dimensions should be placed under a single dimension. It follows that in this dimension, professional agency includes the notion that professionals are responsible actors who exert influence at work in a variety of ways.

Developing work practices. The second dimension combines the theoretically based dimensions of Participation in shared work practices and Transformation of work practices. It therefore captures participatory activities that can take the form of bringing up one's own opinions in work environments, plus collaborating and participating in the developmental actions of the work environment (Collin et al. 2015; Smith 2012). In addition, this dimension refers to agency, for example in the form of making practical suggestions for transforming work practices and trying out new things at work (Haapasaari \& Kerosuo 2015). Thus, the second dimension refers to both developmental activities and participatory activities.

Negotiating professional identity encompasses the notion that agency is manifested via enacting one's professional interests and goals, and also via advancing one's career at work. Thus, this dimension includes the idea that professionals are active constructors and negotiators of their professional identities and careers (e.g. Vähäsantanen et al. 2017a). It originally included two theoretically based dimensions (Negotiating 
professional identity and Constructing a professional career). However, it came to be labelled as merely Negotiating professional identity, since most of items referred to professional identity.

Professional agency has emerged as a fairly novel phenomenon in the fields of workplace learning and working life studies (Goller \& Paloniemi 2017). In addition to professional agency, we recognize that various other concepts have been used to address (theoretically or empirically) the phenomenon in question, encompassing the fact that individuals make intentional choices related to their work and carry out activities in relation to individual and organizational development. For instance, agency-related constructs include proactive behaviour or proactivity at work (e.g. Parker \& Bindle 2017), and job crafting (Tims et al. 2012). One could suggest that these constructs partly overlap with each other and also cover perspectives similar to those of professional agency, particularly in the case of Developing work practices. For example, both constructs of professional agency and job crafting involve matter of learning new things at work. Correspondingly, one could say that the dimension of Influencing at work partly overlaps with the construct of employee influence at work (e.g. Gallie 2009). However, in encompassing all three dimensions mentioned above, professional agency can be regarded as something more comprehensive, and also distinct from these other work-related constructs. In particular, professional agency includes a professional identity perspective on work that is neglected in the other constructs.

Up to now, empirical studies on professional agency have been conducted in a range of professional contexts; however, these investigations have been carried out in specific work environments and/or professional domains (see Goller \& Paloniemi 2017). In this sense, professional agency is acknowledged as a context and situation-based construct. Nevertheless, our previous study (Vähäsantanen et al. 2019) showed that it would be possible to develop a valid measure to investigate professional agency in different professional domains. The present study followed on from this previous work by (i) abbreviating the original PAM, and (ii) testing the invariance of the short version of PAM across the professional domains, and finding also the mean differences between them. Our first assumption was that this measure could indeed be shortened, since not all the items were particularly functional in the original version (Vähäsantanen et al. 2019). Pursuing our aim of removing items, our second assumption was that the factorial structure obtained from the remaining items would be similar across three professional domains, with regard to loadings, item intercepts, and residual variances, thus meeting the criteria of strict invariance (Meredith 1993). Due to the lack of previous research, we did not form an assumption regarding the mean differences between professional domains.

\section{Work engagement}

Since the start of this millennium, work engagement has received considerable attention from researchers and practitioners (e.g. Mustomäki et al. 2013). Originally, Schaufeli et al. (2002) introduced vigor, dedication, and absorption as the three dimensions comprising work engagement. Vigor refers to high levels of energy while working, and persistence in facing challenges or difficulties. Dedication means strong involvement in one's work and a sense of significance, enthusiasm, and inspiration. Absorption is characterized by being fully concentrated and deeply engrossed in one's work. Viewed in this 
light, work engagement was originally understood and measured as a three-dimensional phenomenon (Schaufeli et al. 2002), but later also as a one-dimensional phenomenon (Schaufeli et al. 2019).

In its early phases, work engagement was understood mainly as a persistent affective-cognitive state that is not centred on any specific event, behaviour, or situation. Thus, it was seen as a relatively stable phenomenon involving a positive work-related state of mind (Bakker \& Demerouti 2008; Schaufeli et al. 2002). Recently, work engagement has been understood as a more momentary or temporal phenomenon (Sonnentag et al. 2010). In this study, we understand work engagement as involving temporal phenomena, as is the case also with professional agency.

This study explored the relationship between professional agency and work engagement, understanding both to cover individuals' experiences of their work, but from different perspectives. Due to the theoretical differences bound up with the phenomena, in the validation process, we assumed work engagement (considered as a more emotionally related phenomenon) and professional agency (considered as notably an action-based phenomenon) to be separate constructs, requiring independent measures with different instruments. We further assumed professional agency to be positively related to work engagement. This assumption was based on various notions. In the first place, a mainly strong and positive relationship has been found between work engagement and several working life phenomena, such as job crafting, such that job crafting is often examined as a predictor of work engagement (e.g. Bakker et al. 2012; Tims et al. 2012). Since job crafting may be seen as partly overlapping with the second dimension of professional agency (Developing work practices), there is reason to assume a positive relationship between this dimension and work engagement. Furthermore, since identity and work engagement are seen as related within work organizations (e.g. Popova-Nowak 2010), it seems reasonable to assume that the third dimension of professional agency (Negotiating professional identity) is positively connected to work engagement. Based on these notions, we wished to explore work engagement as a potential outcome of professional agency. However, in the absence of previous quantitative studies, we formulated no assumption regarding the actual magnitude of the association between work engagement and professional agency.

\section{Methods}

\section{Data collection}

The data were collected via a web-based questionnaire during the period 2017-2018. Prior to data collection, the participating work organizations were informed about the study, and their managers signed the consent forms. Subsequently, their personnel were given information on the study (involving voluntary participation), including its goals plus ethical considerations. The questionnaire was then sent to the personnel via an email. The email introduced the description of the data collection, and included a separate link allowing the questionnaire to be completed anonymously.

We obtained the data $(N=449)$ from professional domains of healthcare $(n=168$; i.e. nurses, physicians, laboratory personnel), real estate services $(n=109$; i.e. assemblers, construction site managers), and IT ( $n=172$; i.e. software developers, project engineers). The overall response rate was $35 \%$, but it ranged from $25 \%$ (IT) through 
$46 \%$ (healthcare) to $48 \%$ (real estate services). The respondent profiles (in terms of gender, age, and educational level) were equivalent to the general and domain-specific employee distributions in Finland (Lehto \& Sutela 2014).

The professional domains differed significantly in terms of gender, age, educational level, and work experience within the current work organization (Table 1). Male respondents dominated in the domains of real estate services and IT, while female respondents dominated in the healthcare sector. The age distribution among all the respondents was broadly as follows: $27 \%$ belonged to the age group $30-39,28 \%$ were aged $40-49$, and $24 \%$ were aged $50-59$. The majority of the respondents working in IT were under 40 years of age, whereas more than half of the real estate service respondents were aged $50+$ years.

Table I Descriptive statistics for background factors

\begin{tabular}{|c|c|c|c|c|c|c|c|}
\hline \multicolumn{2}{|c|}{ Background factors } & \multicolumn{2}{|c|}{$\begin{array}{c}\text { Healthcare } \\
(n=168)\end{array}$} & \multicolumn{2}{|c|}{$\begin{array}{l}\text { Real estate services } \\
(n=109)\end{array}$} & \multicolumn{2}{|c|}{$\begin{array}{c}I T \\
(n=172)\end{array}$} \\
\hline & & $n$ & $\%$ & $n$ & $\%$ & $n$ & $\%$ \\
\hline Gender & Men & 33 & 21 & 79 & 75 & 144 & 84 \\
\hline \multirow[t]{2}{*}{$(N=436)$} & Women & 126 & 79 & 26 & 25 & 28 & 16 \\
\hline & \multicolumn{7}{|c|}{$\chi^{2}(2)=|50.7|$ ***** } \\
\hline Age group & $20-29$ years & II & 7 & 8 & 7 & 38 & 22 \\
\hline \multirow[t]{5}{*}{$(N=437)$} & $30-39$ & 37 & 24 & 19 & 18 & 63 & 37 \\
\hline & $40-49$ & 52 & 33 & 25 & 23 & 43 & 25 \\
\hline & $50-59$ & 40 & 25 & 43 & 40 & 22 & 13 \\
\hline & $60+$ & 17 & 11 & 13 & 12 & 6 & 3 \\
\hline & \multicolumn{7}{|c|}{$\chi^{2}(8)=59.05^{* * * *}$} \\
\hline Level of education & Low $^{a}$ & 17 & 11 & 31 & 29 & 13 & 7 \\
\hline \multirow[t]{3}{*}{$(N=440)$} & Medium ${ }^{b}$ & 91 & 56 & 63 & 59 & 108 & 63 \\
\hline & Highc & 54 & 33 & 12 & 11 & 51 & 30 \\
\hline & \multicolumn{7}{|c|}{$\chi^{2}(4)=37.63$} \\
\hline Work experience & 0-9 years & 92 & 61 & 52 & 48 & 151 & 88 \\
\hline \multirow[t]{3}{*}{$(N=430)$} & $10-19$ & 42 & 28 & 23 & 21 & 17 & 10 \\
\hline & $20+$ & 16 & 11 & 33 & 31 & 4 & 2 \\
\hline & \multicolumn{7}{|c|}{$\chi^{2}(4)=74.55$} \\
\hline Position & Supervisors & 25 & 16 & 17 & 16 & 36 & 21 \\
\hline \multirow[t]{2}{*}{$(N=44 I)$} & Employees & 135 & 84 & 92 & 84 & 136 & 79 \\
\hline & \multicolumn{7}{|c|}{$\chi^{2}(2)=2.04$} \\
\hline
\end{tabular}

Note. ${ }^{a}$ certificate from upper-secondary school; bdegree from vocational college or polytechnic, or a bachelor's degree from a university; 'at least a master's university degree or equivalent degree from a polytechnic. $* * * * * 0.00$ I.

The educational level of the respondents was fairly high: the majority (59\%) had a medium level degree (i.e. from a vocational college or polytechnic, or a bachelor's degree from a university) while $14 \%$ had a qualification below this (i.e. graduation from uppersecondary school). As shown in Table $1,27 \%$ of the respondents had completed (at 
least) a master's university degree, or an equivalent degree from a polytechnic. The educational level was lower among the real estate service respondents as compared to the IT and healthcare respondents.

The real estate service respondents also had the longest work experience in the current work organization: more than half of them had been employed for at least 10 years in their current work organization (Table 1). By contrast, the majority of the IT-sector respondents had a maximum of nine years in their current work organization. Eighteen percent of all the respondents in the data held the official position of a supervisor (i.e. they had subordinates working under them), and the distribution was similar across the three professional domains.

\section{Measures}

\section{Professional agency}

The original Professional Agency Measure (see Table 2) covered three dimensions. All the items were rated on a 5-point Likert scale ranging from 1 (I strongly disagree) to 5 (I strongly agree). The terms work community and unit were used in some items. Before presenting the items in the questionnaire, it was explained that the work community referred to 'the community consisting of co-workers that you collaborate with' (e.g. within a project), and that unit referred to, for example, one's company or work unit.

Table 2 The dimensions of professional agency, based on 17 items

\begin{tabular}{|c|c|}
\hline Dimensions & Items \\
\hline Influencing at work & $\begin{array}{l}\text { I. I. I can participate in the preparation of matters in my unit.* } \\
\text { I.2. I can make decisions regarding my own work. } \\
\text { I.3. I can participate in the decision making in my unit.* } \\
\text { 2. I. My opinion is taken into consideration in my unit. } \\
\text { 2.2. My views are taken into consideration in the work community. } \\
\text { 2.3. I am heard in matters relating to my own work.* }\end{array}$ \\
\hline Developing work practices ${ }^{a}$ & $\begin{array}{l}\text { 3. I. I ask or comment actively in my unit.* } \\
\text { 3.2. I actively bring up my own opinions in the work community. } \\
\text { 3.3. I actively collaborate with others in my unit.* } \\
\text { 3.4. I take part in the development of my unit's actions. } \\
\text { 4. I. I develop my ways of working. } \\
\text { 4.3. I make developmental suggestions regarding collective work practices.* } \\
\text { 4.4. I try out new ideas in my work. }\end{array}$ \\
\hline $\begin{array}{l}\text { Negotiating professional } \\
\text { identity }\end{array}$ & $\begin{array}{l}\text { 5.2. I can act according to my own values in my work.* } \\
\text { 5.3. I can realize my professional goals in my work.* } \\
\text { 5.4. In my work I can focus on things that interest me.* } \\
\text { 6.2. I can advance my career in my work. }\end{array}$ \\
\hline
\end{tabular}

Note. *Item included also in the short version of PAM. ${ }^{\text {TT }}$ The revised name of this second dimension (based on the results of this study) is Participation at work.

The research leading to the original PAM showed the measure to be sufficiently applicable, both theoretically and methodologically (Vähäsantanen et al. 2019). However, the research also suggested a need to test the functionality of some of the items. This 
need emerged in the first place because the following items cross-loaded between the dimensions: item 1.2 (dimensions $3 \& 1$ ), items 2.2 and 2.3 (dimensions $1 \& 3$ ), item 3.4 (dimensions $2 \& 1$ ), and items 4.1 and 4.4 (dimensions $2 \& 3$ ). We decided not to remove these items from the original PAM, as we wanted to see how they would behave in further research.

A further point was that in the case of two of the dimensions, residual covariances were obtained between some items belonging to the same dimensions. Overall, three residual covariances between items were found with regard to items 2.1 and 2.2, items 3.1 and 3.2, and items 4.3 and 4.4. In the cases of the first two residual covariances, one could say that the items were conceptualized in a fairly similar way (see Table 2), even if they aimed to address professional agency at different levels (i.e. in the unit and in the work community). Furthermore, the intercepts of the items 1.2, 2.3, 3.4, and 4.4 were not invariant across the rescue services and IT domains. Considerations of this kind underlined the need for further research to validate the dimensions of professional agency, and to confirm the items that applied to them.

\section{Work engagement}

Work engagement $(\alpha=0.82)$ was measured using three items drawn from the UWES-3 measure (Schaufeli et al. 2019): (i) 'At my work, I feel bursting with energy' (vigor), (ii) 'I am enthusiastic about my work' (dedication), and (iii) 'I am immersed in my work' (absorption). The items were rated on a 7-point scale ranging from 0 (never) to 6 (every day). This study considered work engagement as one-dimensional phenomenon, because it used the UWES-3 measure. This short measure cannot demonstrate the original threedimensional nature of work engagement (Schaufeli et al. 2002).

\section{Data analysis}

In constructing the short version of the measure of professional agency (see Table 2), the reduction of items was based on several criteria. Information from the original PAM research (Vähäsantanen et al. 2019) on each of the three original dimensions was considered from two points of view. We first explored which of the items (i) were most strongly related to each of the original PAM dimensions, and (ii) did not show any statistical problems. Secondly, we explored which of the items were most problematic from a statistical point of view (i.e. cross-loading on two or more dimensions, having a residual covariance with any other item, and/or not meeting the criteria of strong, and perhaps also strict, invariance).

In addition, based on the present data, a confirmatory factor analysis (CFA) measurement model was specified for each original dimension. The aim here was to explore whether the loading pattern of the items in each dimension resembled the pattern found in the study by Vähäsantanen et al. (2019). In other words, we considered it necessary to determine which of the items loaded strongest and weakest on each dimension. Finally, there was a requirement that all items chosen for the short PAM should meet a strict invariance criterion (i.e. factor loadings, item intercepts, and residual variances should be equal across our three professional domains; Meredith 1993). Having 
carefully considered all of these criteria, we selected the items to be included in the shortened PAM.

Next, two competing short PAM models were compared: (i) a model that assumed that all the remaining PAM items weighed on one single professional agency factor (M1), and (ii) a model that assumed three correlated factors (M2). These nested models were compared via the Satorra-Bentler $\chi^{2}$ difference test (Satorra \& Bentler 2001) to assess the best-fitting model. A significant $\chi^{2}$ difference test would indicate that the model with fewer degrees of freedom (i.e. M2) fitted better with the data, whereas a nonsignificant $\chi^{2}$ difference test would indicate that the model with more degrees of freedom (i.e. M1) fitted better with the data.

The measurement invariance of the shortened PAM across the three professional domains was investigated via the following models, evaluated successively (Meredith 1993): (i) a configural invariance model (with factor loadings, intercepts, and residual variances of the items being freely estimated, having the latent variances constrained to 1 , and the latent means constrained to 0); (ii) a weak invariance model (with loadings constrained to be the same across the professional domains); (iii) a strong invariance model (with loadings and item intercepts constrained to be equal across the professional domains); (iv) a strict invariance model (with loadings, item intercepts and item residuals constrained to be equal across the professional domains); (v) invariance of factor variances and covariances (all previous steps plus factor variances and covariances constrained to be equal across the professional domains); (vi) invariance of factor means (all previous steps plus factor means constrained to be equal across the professional domains). In each step, the preceding model served as a reference. These nested models were compared via the Satorra-Bentler $\chi^{2}$ difference test (Satorra $\&$ Bentler 2001) to assess the best-fitting model.

After determining the optimal shortened PAM model which would function similarly across the three professional domains, the reliability of the shortened dimensions and of the whole scale was assessed by computing Cronbach's alpha coefficients for each dimension separately. Reliability was considered good if the alpha coefficient was above 0.70 (see Nunnally \& Bernstein 1994).

The convergent and discriminant validity of the structure of the shortened PAM was investigated in relation to work engagement. Prior to the examinations, the measurement model for work engagement was examined using CFA and found to be satisfactory $\left(\chi^{2}(0)=0, p=1.00\right.$; RMSEA $=0.00, \mathrm{CFI}=1.00$; TLI $=1.00 ;$ SRMR $=0.00$, i.e. the model was a saturated model) (see Figure 1). Convergent validity was examined via structural equation modelling, by specifying a model in which the dimensions of PAM were set to correlate with work engagement. The strengths of the correlations were compared to each other via Wald's test, and Cohen's $q$ (Cohen 1988) was used as a measure of the effect size. The discriminant validity was assessed by the Fornell-Larcker method (Fornell \& Larcker 1981). This method requires comparison of the average variance extraction (AVE) estimate of each latent construct with the shared variance (i.e. squared correlations) between the latent construct of interest and all the other latent constructs in the estimated model. The AVE estimate is the average amount of variance that a latent construct is able to explain in those observed items to which it is theoretically related. The AVE estimate of a latent construct is computed as the average of the squared loadings of those items that theoretically relate to that particular latent construct. The discriminant validity can be regarded as sufficient if the latent construct's AVE is greater than the variance it shares with all the other latent constructs in the model.

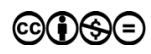


The goodness-of-fit of the tested CFA models was evaluated with the $\chi^{2}$ test, the Comparative Fit Index, CFI (Bentler 1990), the Tucker-Lewis Index, TLI (Tucker \& Lewis 1973), Root-Mean-Square Error of Approximation, RMSEA (Steiger 1990), and Standardized Root-Mean-Square Error, SRMR (Hu \& Bentler 1995). Values < 0.08 for RMSEA and the SRMR, and values $>0.90$ for both the TLI and the CFI are considered to represent an acceptable model fit (Hu \& Bentler 1999).

All the analyses were performed using the MPlus program, version 8.0 (Muthén \& Muthén 1998-2017). The Maximum Likelihood Estimator with robust standard errors was used as an estimator, as the PAM items were skewed. The Full-InformationMaximum-Likelihood procedure was used to account for missing data (Enders 2010).

\section{Results}

\section{The short version of PAM: reduction of items}

To reduce the number of the items of the original PAM, an iterative process was carried out separately for each dimension. According to Vähäsantanen et al (2019), the most characteristic items (i.e. having the highest loadings) in the first of the original PAM dimensions (Influencing at work) were items 1.1 and 1.3 (see Table 2). These items did not show any statistical problems. Hence, these items were retained in the new version of the PAM.

The most problematic items in the first of the original PAM dimensions were items 1.2 and 2.2. Item 1.2 loaded on two different dimensions (1 and 3), and it did not meet the criteria of strong invariance, thus suggesting that the response style between the professional domains of rescue services and IT was different. Item 2.2 also crossloaded on dimensions 1 and 3. Furthermore, it had a strong residual covariance with item 2.1. This was most likely due to the similarity of the wording in the two items (see Table 2). On the basis of these problems, items 1.2 and 2.2 were excluded from the short version of the PAM. Thus, our initial set of items for the first shortened dimension of PAM included items 1.1, 1.3, 2.1, and 2.3. However, we also had to exclude item 2.1, as it did not meet the strong invariance criteria in the invariance comparison test conducted with all the items to be included in the shortened PAM. Hence, the final set included items 1.1, 1.3, and 2.3. We decided to retain the name of this first dimension (Influencing at work), since these three items well reflect the original name of the dimension.

In the second original PAM dimension (Developing work practices, see Table 2), items 3.1, 3.2, and 4.3 seemed to characterize this dimension relatively well in the study by Vähäsantanen et al. (2019). Furthermore, these items did not show any statistical problems. In contrast, the most problematic items in the second original dimension were items 3.4, 4.1, and 4.2. All these three items cross-loaded on two different dimensions: item 3.4. on dimensions 1 and 2, and items 4.1 and 4.4 on dimensions 2 and 3. Item 4.4 had a strong residual correlation with item 4.3. In addition, it and also item 3.4 did not meet the strong invariance criterion (suggesting that the response style between the professional domains rescue services and IT was different in these two items). On the basis of these problems, items 3.4, 4.1, and 4.4 were excluded from the short measure. At this point, the remaining items were 3.1, 3.2, 3.3, and 4.3. Out of these, we decided 
also to drop item 3.2, as its wording differed from the wording of the other items: item 3.2. addressed professional agency at the level of the work community, whereas all the other items addressed professional agency at the unit level. Thus, the second dimension of the short version of the PAM included items 3.1, 3.3, and 4.3.

In the case of this second dimension, the original name Developing work practices seemed unsuitable, after consideration of the items for inclusion in the short version relating to this second dimension. The original dimension included seven items and was based on two theoretical dimensions (i.e. Participation in shared work practices and Transformation of work practices, see Section 1.1). However, the items that were included in the short version of PAM reflected participation more strongly than development-oriented activities. For this reason, we renamed the second dimension as Participation at work.

The third original PAM dimension (Negotiating professional identity) included four items (see Table 2). Out of these, items 5.3 and 5.4 provided the best characterization of the dimension. However, items 5.2 and 6.2, too, had shown relatively high loadings on this dimension in the study by Vähäsantanen et al. (2019). As none of the four items had presented statistical problems in the previous validation article, all of them could have been included in the new version of PAM. However, we had to exclude item 6.2 from the final set of items for the third dimension, since it did not meet the strong invariance criterion in the invariance comparison tests conducted with all the items of the shortened PAM. Hence, the final set of items for the third dimension included items 5.2, 5.3, and 5.4. Since the three items well reflected the original name (Negotiating professional identity), the name was retained.

Next, two competing measurement models M1 and M2 were constructed and compared. In M1, all the remaining nine items weighed on one factor, whereas in M2, three correlated factors were formed. Items $1.1,1.3$, and 2.3 were set to load on factor 1 , items 3.1,3.3, and 4.3 were set to load on factor 2, and items 5.2-5.4 were set to load on the third factor. As shown in Table 3 (section a), M1 fitted poorly with the data, whereas the fit of M2 was fairly good. Because the $\chi^{2}$ difference test also supported M2 (Table 3), M2 with three correlated factors was considered superior to M1, and it was chosen as the best measurement model. ${ }^{1}$ The reliabilities for the three dimensions (see Figure 1) and the entire scale $(\alpha=0.85)$ were acceptable. This three-dimensional model served as a starting point for further analyses.

Table 3 Fit index values and $\chi^{2}$ difference tests from (a) comparison of competing PAM measurement models, and (b) multiple group examinations of the measurement invariance of the short version of PAM across the professional domains of health care $(n=168)$, real estate services $(n=109)$, and IT $(n=172)$.

Nested models $\quad \chi^{2} \quad$ df $\begin{gathered}\text { Scaling } \\ \text { correction }\end{gathered}$ CFI TLI RMSEA SRMR $\chi^{2}$ difference

a) Competing PAM measurement models

\begin{tabular}{lcccccccc}
$\begin{array}{l}\text { One-factor model } \\
(\mathrm{MI})\end{array}$ & 410.11 & 27 & 1.18 & 0.70 & 0.60 & 0.18 & 0.10 & $\begin{array}{c}\text { Comparison of } \\
\text { MI vs. M2: }\end{array}$ \\
$\begin{array}{l}\text { Three-factor model } \\
(\mathrm{M} 2)\end{array}$ & 91.34 & 24 & 1.20 & 0.950 .92 & 0.08 & 0.05 & $\begin{array}{c}\Delta \chi^{2}(3)=371.66, \\
p<0.001\end{array}$ \\
\hline
\end{tabular}




\begin{tabular}{|c|c|c|c|c|c|c|c|c|}
\hline Nested models & $\chi^{2}$ & $d f$ & $\begin{array}{c}\text { Scaling } \\
\text { correction }\end{array}$ & CFI & TLI & RMSEA & SRMR & $\begin{array}{c}\chi^{2} \text { difference } \\
\text { test }\end{array}$ \\
\hline \multicolumn{9}{|l|}{ b) Invariance levels } \\
\hline None (configurala) & 147.86 & 72 & 1.13 & 0.94 & 0.91 & 0.08 & 0.06 & - \\
\hline Loadings (weak) & 157.24 & 84 & 1.15 & 0.95 & 0.93 & 0.08 & 0.08 & $\begin{array}{c}\Delta \chi^{2}(12)=11.14, \\
p=0.517\end{array}$ \\
\hline $\begin{array}{l}\text { Loadings, intercepts } \\
\text { (strong) }\end{array}$ & 177.36 & 96 & 1.13 & 0.94 & 0.93 & 0.08 & 0.09 & $\begin{array}{c}\Delta \chi^{2}(12)=19.85, \\
p=0.070\end{array}$ \\
\hline $\begin{array}{l}\text { Loadings, intercepts, } \\
\text { residual variances (strict) }\end{array}$ & 193.04 & 114 & 1.17 & 0.94 & 0.94 & 0.07 & 0.10 & $\begin{array}{c}\Delta \chi^{2}(18)=18.08, \\
p=0.450\end{array}$ \\
\hline $\begin{array}{l}\text { Loadings, intercepts, } \\
\text { residual variances, factor } \\
\text { variances/covariances }\end{array}$ & 210.12 & 126 & 1.17 & 0.94 & 0.95 & 0.07 & 0.14 & $\begin{array}{c}\Delta \chi^{2}(12)=17.05, \\
p=0.148\end{array}$ \\
\hline $\begin{array}{l}\text { Loadings, intercepts, } \\
\text { factor variances/ } \\
\text { covariances, factor } \\
\text { means }\end{array}$ & 233.00 & 132 & 1.16 & 0.92 & 0.94 & 0.07 & 0.16 & $\begin{array}{c}\Delta \chi^{2}(6)=25.49 \\
p<0.001\end{array}$ \\
\hline
\end{tabular}

Note. $\Delta=$ difference.

\section{The short version of PAM across professional domains}

Strict invariance plus invariance of factor variances and covariances was obtained for the structure of the shortened PAM across the professional domains of health care, real estate services, and IT (Table 3, section b). This is important, as our third aim was to examine the dimensions of professional agency in relation to work engagement, in order to assess convergent and discriminant validity. These examinations would not be valid in the absence of invariance between the factor variances/covariances of the dimensions of professional agency (Meredith 1993).

The final invariance test revealed differences between professional domains in the means of the abbreviated professional agency dimensions (Table 3, section b). IT personnel reported higher level of Influencing at work and Negotiating professional identity than was the case among healthcare personnel ( $p$ for Influencing at work $=0.011$ and for Negotiating professional identity $=0.005)$ and real estate service personnel $(p$ for Influencing at work $=0.026$ and for Negotiating professional identity $=0.003$ ). The respondents across all three domains reported having a similar level of Participation at work.

\section{Convergent and discriminant validity of the short PAM in relation to work engagement}

Finally, the convergent and discriminant validity of the shortened PAM in relation to work engagement was examined. The model showed an adequate fit to the data $\left(\chi^{2}(46)=\right.$ $139.12, p<0.001$; RMSEA $=0.07$, CFI $=0.95$; TLI $=0.94$; SRMR $=0.05)$. The associations of the dimensions of the shortened PAM with work engagement were all 
statistically significant and positive: the greater the influencing at work, participation at work, and the negotiation of professional identity reported by participants, the greater was their work engagement (Figure 1). Participation at work had a weaker association with engagement than the other two dimensions. However, the effect sizes (see Table 4) of the differences between the correlations were small between the Participation at work and Influencing at work associations, large between the Participation at work and Negotiating professional identity associations, and between the Influencing at work and Negotiating professional identity associations (Cohen 1988). Overall, the results suggest that the three professional agency dimensions are closely and positively linked to work engagement, thus showing convergent validity in relation to work engagement.

Figure I The short version of PAM in relation to work engagement $(N=449)$. All estimates are standardized, and their $p$ values $<0.001$.

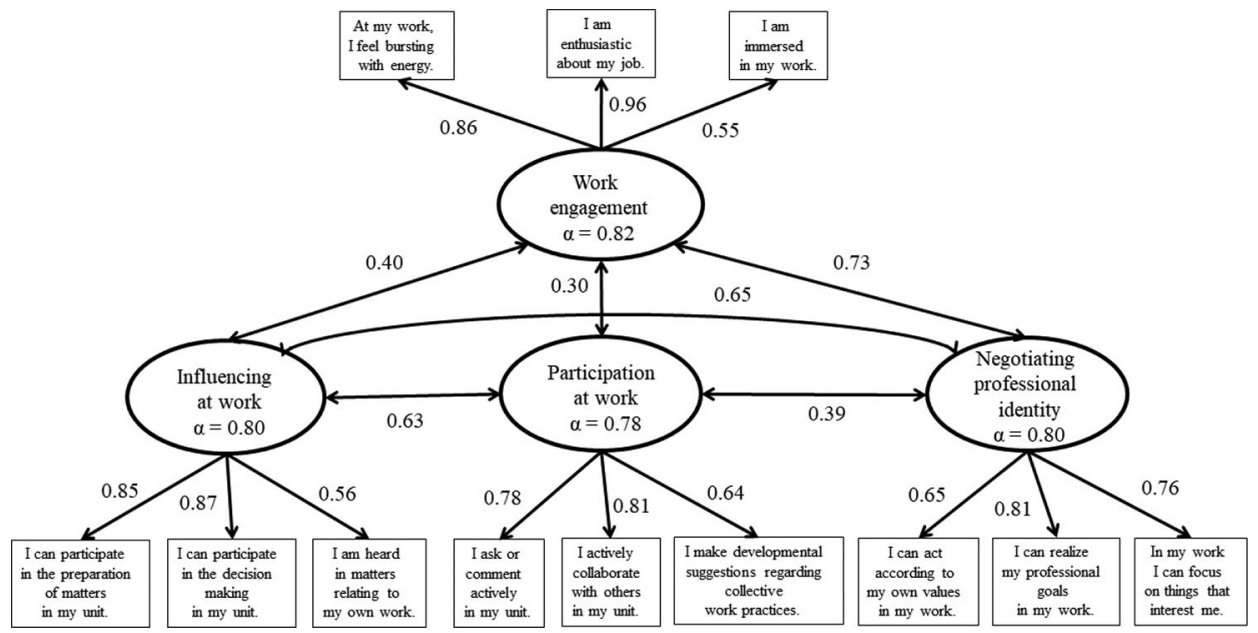

The results from the discriminant validity examinations of the short PAM in relation to work engagement are shown in Table 4. ${ }^{2}$ The AVE for each dimension was higher than its shared variance with work engagement. In other words, the discriminant validity of the structure of the short measure of professional agency could be regarded as confirmed, and the dimensions of professional agency could be regarded as distinct from work engagement, even if they are closely connected.

Table 4 Correlations ( $r$ ), average variance extracted (AVE), and estimated amount of shared variance between all the short dimensions of professional agency and work engagement $(N=449)$

\begin{tabular}{llcccc}
\hline Factors & $\mathbf{I}$ & $\mathbf{2}$ & $\mathbf{3}$ & $\mathbf{4}$ \\
\hline I & Influencing at work & $\mathbf{0 . 5 9}$ & 0.40 & 0.42 & 0.20 \\
2 & Participation at work & $0.63 * * *$ & $\mathbf{0 . 5 6}$ & 0.15 & 0.09 \\
3 & Negotiating professional identity & $0.65 * * * *$ & $0.39 * * * *$ & $\mathbf{0 . 5 5}$ & 0.53 \\
4 & Work engagement & $0.40 * * * *$ & $0.30 * * * *$ & $0.73 * * * *$ & $\mathbf{0 . 6 5}$ \\
\hline
\end{tabular}




\begin{tabular}{|c|c|c|c|c|}
\hline Factors & $\mathbf{I}$ & 2 & 3 & 4 \\
\hline $\begin{array}{l}\text { Comparison of the strength of the } \\
\text { correlations }(r) \text { between the dimensions } \\
\text { of the PAM and work engagement }\end{array}$ & & $r_{14}$ vs. $r_{24}$ & $r_{14}$ Vs. $r_{34}$ & $r_{24}$ vs. $r_{34}$ \\
\hline Wald's test: $\chi^{2}(1)$-value & & 6.73**⿻丷木 & 0.34 & 11.92 ***** \\
\hline
\end{tabular}

Note. ${ }^{* *} p<0.01$, $* * * * p<0.001$. Correlations between the factors are below the diagonal, shared variance (i.e. squared factor correlations) above the diagonal, and AVE estimates are presented on the diagonal (in bold).

\section{Discussion and conclusions}

Professional agency is becoming an increasingly relevant topic in work organizations and in the professional lives of individuals (Goller \& Paloniemi 2017). However, there has up to now been no comprehensive but brief instrument to assess it, and or to shed light on how it is experienced in current working life. To contribute to research on professional agency, our study aimed to construct a short measure to explore professional agency in work organizations, based on the longer version of the Professional Agency Measure (PAM), and applied across professional domains. The further aim was to illustrate the convergent and divergent validity of the short PAM when the work engagement construct was included.

\section{Theoretical discussion}

The results indicated that the development of the original version of PAM towards a shorter 9-item measure was successful. As we had assumed, the original PAM could be shortened, and the short PAM was judged to be applicable for use as a measure of professional agency. This conclusion was primarily supported by the fact that the reliability of the three shortened dimensions (Influencing at work, Participation at work, and Negotiating professional identity) was acceptable. Since reduction of the items did not decrease reliability, the short version of PAM is definitely worth considering for use in future investigations. It should also be noted that the eight items that were removed were mainly those whose functionality had emerged as problematic in the original study (Vähäsantanen et al. 2019), with many of these items cross-loading on two dimensions, and also showing a different response style between the professional domains. The procedures in this study were mostly able to eradicate these problems.

Professional agency has often been approached as a one-dimensional phenomenon, with investigations focusing on a single point of view. The focus could involve, for example, influencing, making a difference, participation, belonging, constructing a career, or negotiating one's professional identity (e.g. Goller \& Paloniemi 2017). It can thus be suggested that the academic community has lacked a sufficiently elaborated, multidimensional understanding of professional agency. This study found support for a three-dimensional professional agency structure; according to a priori assumption, this structure emerged as similar across samples from three domains, namely healthcare, real estate services, and information technology. 
The three-dimensional structure of professional agency obtained mostly reflects the original theoretically oriented three-dimensional structure (Eteläpelto et al. 2013; Vähäsantanen et al. 2019). As a consequence of the reduction from the items, the third dimension of professional agency (Negotiating professional identity) nevertheless reflects professional identity more clearly, since it no longer covers career prospects. The reduction also required modification of the name of the second dimension (original name: Developing work practices). It was renamed as Participation at work, on the grounds that this reflected the three items included in the dimension better than the original name (see the second dimension in Table 2, items with an asterisk). In its current form, the second dimension is more clearly distinguished from learning at work, which is often understood as the (trans)forming of work practices and processes, including, for example, 'trying out new ideas at work' (e.g. Billett 2011; Tynjälä 2013). Furthermore, the second dimension corresponds well with current literature, in which participation is theorized as one of the main elements of professional agency in work environments (Damsa et al. 2017; Eteläpelto 2017; Goller \& Billett 2014).

To sum up, the three (now revised) dimensions of professional agency are Influencing at work, Participation at work, and Negotiating professional agency. It can be argued that up to now, perspectives on professional agency have often appeared to be one-dimensional. Thus, no individual (quantitative or qualitative) investigation has so far addressed all these dimensions. On this basis, it can be claimed that this paper contributes to theory on professional agency (i) by confirming the multidimensional structure of professional agency, and (ii) by providing a more coherent theoretical definition of professional agency. This elaborated definition no longer includes career perspectives and learning-related activities.

According to our results, the structure of the shortened PAM was indeed similar across professional domains. However, the results pointed to some differences between professional domains, with the levels of Influencing at work and Negotiating professional identity emerging as higher among IT personnel than among healthcare and real estate service personnel. Speculatively, one could say that - compared to healthcare and real estate services - the domain of IT contains creative and flexible work, with more opportunities for influencing individual and collective work-related matters and for enacting professional interests and goals. It seems reasonable to suppose that healthcare and real estate involve more traditional and possibly hierarchical professional structures, requiring relatively controlled and routine ways of working. On the other hand, the mean differences between the professional domains were not observed in the case of Participation at work. This implies that, compared to the other two dimensions, this dimension is not so domain-specific in terms of the extent of professional agency in different work environments. Overall, our study indicated that the short version of PAM measures the same phenomenon (i.e. professional agency) in each professional domain, but that the extent of its dimensions was, in part, reported differently across the domains.

Furthermore, as assumed a priori, our results indicated that the three shortened dimensions of professional agency are theoretically and empirically fairly distinct from but closely and positively linked to work engagement. In other words, they are intertwined but analytically separate. Note that although professional agency and work engagement can be regarded as separate, there reason to consider their close relationship in more detail. The high correlation between them may derive from the fact that both instruments capture individuals' experiences of work, albeit from different perspectives,

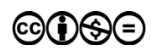


encompassing both emotional and behavioural aspects. In the present study, work engagement was found to be related notably to Negotiating professional identity. This finding is not altogether surprising, being consistent with Popova-Nowak (2010), who proposed that work identity and work engagement are interwoven within organizations. Furthermore, a qualitative study by Ursin et al. (2020) has indicated that individuals experience enthusiasm at work (referring to work engagement characterized by dedication) when they are able to realize their professional interests in the work.

\section{Limitations and future research avenues}

One limitation of the study is that it was conducted solely within Finnish working life, including specific professional domains. There is therefore a need to conduct comparative studies in a range of national contexts, and on a variety of domains. Moreover, the response rate was fairly low, although it is notable that the respondent profiles were equivalent to the general and domain-specific employee distributions in Finland.

A point to bear in mind is, that in line with the theoretical foundations of PAM (Eteläpelto et al. 2013), the items covered professional agency as something that individuals enact within the sociocultural conditions of the work environment, rather than as a set of inner capabilities. Thus, the items can be claimed to appropriately reflect agentic behaviour within the sociocultural opportunities available. Nevertheless, although we see the measure as having a solid theoretical basis, this could be viewed also as a limitation of the study, on the grounds that some items reflect sociocultural opportunities for agency, or a feeling of control over one's actions (i.e. a sense of agency), or job resources, rather than agentic actions per se.

The slightly modified second dimension of professional agency (Participation at work) opens up some new avenues for future research. In its current form, this dimension no longer overlaps with learning at work. Hence, further research could investigate in more detail the nature of the relationships between professional agency and learning at work via validated instruments (e.g. Grosemans et al. 2020). To date, recent qualitative research has assumed a connection between professional agency and work-related learning (Goller \& Paloniemi 2017; Vähäsantanen et al. 2017b). This study further emphasizes the usefulness of a longitudinal research focus on the causal and reciprocal relationship between professional agency and work engagement. For example, empirical research could address whether engaged employees are more likely to enact agency which (depending on the direction of causation) could call into question our speculation above, namely that professional agency, and particularly its dimension of Professional identity negotiation, might actually be a precondition for work engagement.

It would further be interesting to explore how professional agency is intertwined with related constructs such as job crafting (Tims et al. 2012). This kind of investigation would now be more feasible, given that the revised second dimension of professional agency no longer encompasses items overlapping with job crafting (such as 'learning new things at work'). In addition, such research would test the discriminant validity between these constructs. A further point to consider is that, as noted by Eteläpelto (2017), there is only limited empirical evidence regarding professional agency in terms of its transformations and continuities over time. Quantitative longitudinal research would further enrich the theory of professional agency from this perspective. 


\section{Conclusions}

From both a methodological and a pragmatic point of view, it appears that the short nine-item version of PAM is more functional than the longer version. Thus, the study offers a reliable measure, which is relevant across professional domains and which could facilitate research in Nordic work organizations. This could be done without compromising the measure's psychometric qualities. In fact, this short version is more usable in research, since completion is more rapid. It would therefore be easier to include it within national and international surveys aimed at investigating working life. Despite this, use of the longer version would still be advisable, for example, among scholars who wished to investigate the distinct dimensions of professional agency. ${ }^{3}$

We conclude that the academic community could benefit from an elaborated definition of professional agency, and from a valid measure to assess such agency at work, as presented here. The measure comprehensively captures individuals' experiences of their work, including their experience of influencing, participating, and negotiating identity at work. We hope that this research will motivate further scientific advances in the study of professional agency, encompassing also its associations with other work-related phenomena, notably work engagement. Taken together, these aspirations could impact positively on people's professional lives.

\section{References}

Bakker, A. B., \& Demerouti, E. (2008). Towards a model of work engagement, Career Development International 13(3): 209-223. doi: https://doi.org/10.1108/136204308 10870476.

Bakker, A. B., Tims, M., \& Derks, D. (2012). Proactive personality and job performance: The role of job crafting and work engagement, Human Relations 65: 1359 -1378. doi: https:// doi.org/10.1177/0018726712453471.

Bentler, P. M. (1990). Comparative fit indexes in structural models, Psychological Bulletin 107(2): 238-246. doi: https://doi.org/10.1037/0033-2909.107.2.238.

Billett, S. (2008). Learning through work: Exploring instances of relational interdependencies, International Journal of Educational Research 47(4): 32-47. doi: https://doi. org/10.1016/j.ijer.2008.07.006.

Billett, S. (2011). Subjectivity, self and personal agency in learning through and for work. In: M. Malloch, L. Cairns, L. Evans, \& B. O’Connor (eds.) SAGE handbook of workplace learning, London: Sage, pp. 60-72. doi: http://dx.doi.org/10.4135/9781446200940.n5.

Burisch, M. (1984). Approaches to personality inventory construction: A comparison of merits, The American Psychologist 39(3): 214-227. doi: https://doi.org/10.1037/0003066X.39.3.214.

Cohen, J. (1988). Statistical Power Analysis for the Behavioral Sciences, 2nd ed. New York: Routledge. doi: https://doi.org/10.4324/9780203771587.

Collin, K., Paloniemi, S., \& Vähäsantanen, K. (2015). Multiple forms of professional agency for (non)crafting of work practices in hospital organisation, Nordic Journal of Working Life Studies 5(3a): 63-83. doi: https://doi.org/10.19154/njwls.v5i3a.4834.

Damsa, C. I., Froehlich, D. E., \& Gegenfurtner, A. (2017). Reflections on empirical and methodological accounts of agency at work. In: M. Goller \& S. Paloniemi (eds.) Agency at work: An agentic perspective on professional learning and development, Cham: Springer, pp. 445-464. doi: https://doi.org/10.1007/978-3-319-60943-0 22. 
Enders, C. K. (2010). Applied Missing Data Analysis, New York: Guilford Publications. doi: https://doi.org/10.1111/j.1467-842X.2012.00656.x.

Eteläpelto, A. (2017). Emerging conceptualisations on professional agency and learning. In: M. Goller \& S. Paloniemi (eds.) Agency at work: An agentic perspective on professional learning and development, Cham: Springer, pp. 183-201. doi: https://doi. org/10.1007/978-3-319-60943-0 10.

Eteläpelto, A., Vähäsantanen, K. Hökkä, P., \& Paloniemi, S. (2013). What is agency? Conceptualizing professional agency at work, Educational Research Review 10: 45-65. doi: http://dx.doi.org/10.1016/j.edurev.2013.05.001.

Fornell, C., \& Larcker, D. F. (1981). Evaluating structural equation models with unobservable variables and measurement error, Journal of Marketing Research 18(1): 39-50. doi: https://doi.org/10.1177/002224378101800104.

Gallie, D. (2009). Institutional regimes and employee influence at work, Cambridge Journal of Regions, Economy and Society 2(3): 1-15.

Goller, M. (2017). Human Agency at Work: An Active Approach towards Expertise Development, Wiesbaden: Springer. doi: https://doi.org/10.1007/978-3-658-18286-1.

Goller, M., \& Billett, S. (2014). Agentic behaviour at work: Crafting learning experiences. In: C. Harteis, A. Rausch \& J. Seifried (eds.) Discourses on professional learning: On the boundary between learning and working, Dordrecht: Springer, pp. 25-44. doi: https:// doi.org/10.1007/978-94-007-7012-6 3 .

Goller, M., \& Paloniemi, S. (eds.) (2017). Agency at work: An agentic perspective on professional learning and development, Cham: Springer. doi: https://doi.org/10.1007/978-3319-60943-0.

Grosemans, I., Smet, K., Houben, E., De Cuyper, N., \& Kyndt, E. (2020). Development and validation of an instrument to measure work-related learning, Scandinavian Journal of Work and Organizational Psychology 5(1): 3, 1-16. doi: http://doi.org/10.16993/sjwop.99.

Haapasaari, A., \& Kerosuo, H. (2015). Transformative agency: The challenges of sustainability in a long chain of double stimulation, Learning, Culture and Social Interaction 4: 37-47. doi: https://doi.org/10.1016/j.lcsi.2014.07.006.

Harteis, C., Goller, M., \& Caruso, C. (2020). Conceptual change in the face of digitalization: Challenges for workplaces and workplace learning, Frontiers in Education 5(1): 1-10. doi: https://doi.org/10.3389/feduc.2020.00001.

Heiskanen, T., \& Jokinen, E. (2015). Resources and constraints of line manager agency in municipal reforms, Nordic Journal of Working Life Studies 5(3): 79-100. doi: https://doi. org/10.19154/njwls.v5i3.4808.

Hu, L. T., \& Bentler, P. M. (1995). Evaluating model fit. In: R. Hoyle (ed.) Structural equation modeling: Issues, concepts, and applications, Thousand Oaks: Sage, pp. 76-99.

Hu, L. T., \& Bentler, P. M. (1999). Cutoff criteria for fit indexes in covariance structure analysis: Conventional criteria versus new alternatives, Structural Equation Modeling: A Multidisciplinary Journal 6(1): 1-55. doi: https://doi.org/10.1080/10705519909540118.

LaPointe, K., \& Heilmann, P. (2014). 'Daring leaps' Construction of meaning and individual agency in career change narratives in the media, Nordic Journal of Working Life Studies 4(2): 47-64. doi: https://doi.org/10.19154/njwls.v4i2.3864.

Lehto, A-M., \& Sutela, H. (2014). Työolojen muutokset 1977-2013. [Changes in working conditions 1977-2013], Official Statistics of Finland, Helsinki: Statistics Finland.

Marsh, H. W., Muthén, B., Asparouhov, T., Lüdtke, O., Robitzsch, A., Morin, A. J. S., \& Trautwein, U. (2009). Exploratory structural equation modeling, integrating CFA and EFA: Application to students' evaluations of university teaching, Structural Equation Modeling 16(3): 439-476. doi: https://doi.org/10.1080/10705510903008220.

Meredith, W. (1993). Measurement invariance, factor analysis and factorial invariance, Psychometrika 58(4): 525-543. doi: https://doi.org/10.1007/bf02294825. 
Mustomäki, A., Anttila, T., \& Oinas, T. (2013). Engaged or not? A comparative study on factors inducing work engagement in call center and service sector work, Nordic Journal of Working Life Studies 3(1): 49-68. doi: https://doi.org/10.19154/njwls.v3i1.2520.

Muthén, L., \& Muthén, B. (1998-2017). Mplus User's Guide, Los Angeles: Muthén \& Muthén.

Nunnally, J. C., \& Bernstein, I. H. (1994). Psychometric Theory, 3rd ed. New York: McGrawHill. doi: https://doi.org/10.1177/014662169501900308.

Paloniemi, S., \& Goller, M. (2017). The multifaceted nature of agency and professional learning. In: M. Goller \& S. Paloniemi (eds.) Agency at work: An agentic perspective on professional learning and development, Cham: Springer, pp. 465-478. doi: https://doi. org/10.1007/978-3-319-60943-0 23.

Parker, S., \& Bindl, U. K. (Eds.). (2017). Proactivity at work: Making things happen in organizations, New York: Routledge.

Popova-Nowak, I. V. (2010). Work identity and work engagement, Washington, DC: George Washington University. https://www.ufhrd.co.uk/wordpress/wp-content/uploads/2010/ 08/9 5.pdf.

Ruohotie-Lyhty, M., \& Moate, J. (2016). Who and how? Preservice teachers as active agents developing professional identities, Teaching and Teacher Education 55: 318-327. doi: https://doi.org/10.1016/j.tate.2016.01.022.

Satorra, A., \& Bentler, P. M. (2001). A scaled difference chi square test statistic for moment structure analysis, Psychometrika 66(4): 507-514. doi: https://doi.org/10.1007/ bf02296192.

Schaufeli, W. B., Bakker, A. B., \& Salanova, M. (2006). The measurement of work engagement with a short questionnaire: A cross-national study, Educational and Psychological Measurement 66(4): 701-716. doi: https://doi.org/10.1177/0013164405282471.

Schaufeli, W. B., Salanova, M., Contzalez-Roma, V., \& Bakker, A. B. (2002). The measurement of engagement and burnout: A two sample confirmatory factor analytic approach, Journal of Happiness Studies 3(1): 71-92. doi: https://doi.org/10.1023/A:1015630930326.

Schaufeli, W. B., Shimazu, A., Hakanen, J., Salanova, M., \& De Witte, H. (2019). An ultra-short measure for work engagement: The UWES-3 validation across five countries, European Journal of Psychological Assessment 35(4): 577-591. doi: https://doi.org/10.1027/10155759/a000430.

Smith, R. (2012). Clarifying the subject centred approach to vocational learning theory: Negotiated participation, Studies in Continuing Education 34(2): 159-174. doi: https:// doi.org/10.1080/0158037x.2011.609542.

Sonnentag, S., Dormann, C., \& Demerouti, E. (2010). Not all days are created equal: The concept of state work engagement. In: A. B. Bakker \& M. P. Leiter (eds.) Work engagement: A handbook of essential theory and research, New York: Psychology Press, pp. 25-38.

Stanton, J. M., Sinar, E. F., Balzer, W. K., \& Smith, P. C. (2002). Issues and strategies for reducing the length of self-report scales, Personnel Psychology 55(1): 167-194. doi: https:// doi.org/10.1111/j.1744-6570.2002.tb00108.x.

Steiger, J. H. (1990). Structural model evaluation and modification: An interval estimation approach, Multivariate Behavioral Research 25(2): 173-180. doi: https://doi.org/10.1207/ s15327906mbr2502 4.

Tims, M., Bakker, A. B., \& Derks, D. (2012). Development and validation of the job crafting scale, Journal of Vocational Behavior 80: 173-186. doi: https://doi.org/10.1016/j. jvb.2011.05.009.

Tucker, L. R., \& Lewis, C. (1973). A reliability coefficient for maximum likelihood factor analysis, Psychometrika 38(1): 1-10. doi: https://doi.org/10.1007/BF02291170.

Tynjälä, P. (2013). Toward a 3-P model of workplace learning: A literature review, Vocations and Learning 6(1): 11-36. doi: https://doi.org/10.1007/s12186-012-9091-z. 
Ursin, J., Vähäsantanen, K., McAlpine, L., \& Hökkä, P. (2020). Emotionally loaded identity and agency in Finnish academic work, Journal of Further and Higher Education 44(3): 311-325. doi: https://doi.org/10.1080/0309877X.2018.1541971.

Vähäsantanen, K., Hökkä, P., Paloniemi, S., Herranen, S., \& Eteläpelto, A. (2017a). Professional learning and agency in an identity coaching programme, Professional Development in Education 43(4): 514-536. doi: https://doi.org/10.1080/19415257.2016.1231131.

Vähäsantanen, K., Paloniemi, S., Hökkä, P., \& Eteläpelto, A. (2017b). Agentic perspective on fostering work-related learning, Studies in Continuing Education 39(3): 251-267. doi: https://doi.org/10.1080/0158037X.2017.1310097.

Vähäsantanen, K., Räikkönen, E., Paloniemi, S., Hökkä, P., \& Eteläpelto, A. (2019). A novel instrument to measure the multidimensional structure of professional agency, Vocations and Learning 12(2): 267-295. doi: http://dx.doi.org/10.1007/s12186-018-9210-6.

\section{Notes}

${ }^{1}$ As the correlation between Influencing at work and Negotiating professional identity was fairly high (0.65), we also compared our three-dimensional PAM model to a two-dimensional model with Influencing at work and Negotiating professional identity combined into one dimension. The result $\left(\Delta \chi^{2}(3)=155.84, p<0.001\right)$ supported the three-dimensional model of PAM. Overall, the three-dimensional model emerged as the most reasonable solution.

${ }^{2}$ As the correlation between Negotiating professional identity and work engagement was high, we performed an additional test to examine whether the four-factor model (including the three PAM dimensions and work engagement as separate factors) would outperform a model which with only three factors, i.e. having the PAM dimensions of Influencing at work and Participation at work as separate factors, and a third factor in which the items of Negotiating professional identity were included together with those reflecting work engagement. The result $\left(\Delta \chi^{2}(3)=155.84, p<0.001\right)$ supported the four-factor model, indicating that the PAM measure is distinct from work engagement.

${ }^{3}$ In the case of a longer measure, researchers need to be aware of certain methodological challenges and preconditions. An exploratory factor analytic framework would then be appropriate (see Vähäsantanen et al. 2019), and exploratory structural equation modelling (Marsh et al. 2009) would be recommended. 